\title{
Categorization of object descriptions in Alzheimer's disease and frontotemporal dementia: Limitation in rule-based processing
}

\author{
MURRAY GROSSMAN \\ University of Pennsylvania, Philadelphia, Pennsylvania \\ EDWARD E. SMITH \\ University of Michigan, Ann Arbor, Michigan \\ and \\ PHYLLIS L. KOENIG, GUILA GLOSSER, JINA RHEE, and KARI DENNIS \\ University of Pennsylvania, Philadelphia, Pennsylvania
}

\begin{abstract}
Studies of semantic memory in probable Alzheimer's disease (AD) have focused on the degradation of semantic knowledge, but other work in $\mathrm{AD}$ suggests an impairment in the semantic categorization processes that operate on this knowledge. We examined the categorization of object descriptions, where semantic category membership judgments were based on rule-based or similarity-based categorization processes. We found that $\mathrm{AD}$ patients were selectively limited in their semantic categorization under conditions requiring a rule-based approach. However, AD patients did not differ from healthy seniors under conditions based on judgments of overall similarity. We showed that this was not due to nonspecific or overall task-related difficulty associated with the rule condition by asking the subjects to use similarity-basedjudgments of perceptually degraded versions of the stimuli. The results of this condition did not differ from other similarity-based judgments but did differ from the rule-based condition in $\mathrm{AD}$. Rule-based judgments of semantic category membership correlated with executive measures of inhibitory control and mental search, but not with measures of episodic memory or overall dementia severity, suggesting a contribution of executive resources to rule-based semantic categorization. Moreover, the pattern of limited rule-based categorization in AD closely resembled the performance profile of patients with frontotemporal dementia, further implying that executive resource limitations underlie $\mathrm{AD}$ patients' limited rule-based semantic categorization. These findings suggest that semantic memory difficulty in $\mathrm{AD}$ is due in part to a deficit in executive processes that are central to rule-based categorization in semantic memory.
\end{abstract}

Studies of semantic memory have emphasized the degradation of semantic knowledge in patients with central nervous system disease (for reviews, see Grossman \& Koenig, in press; Humphreys \& Forde, 2001; and Saffran \& Schwartz, 1994). However, this work has not fully explained the comprehension difficulty that is found in common neurodegenerative conditions such as probable Alzheimer's disease (AD). Given observations that comprehension is among the most important predictors of end-points, such as the need for nursing home placement, in AD (Chan, Salmon, Butters, \& Johnson, 1995), it is crucial to identify additional factors that contribute to impaired semantic memory in these patients. In the present study, we investi-

This work was supported in part by Grants AG15116, AG17586, and NS35867 from the U.S. Public Health Service. Correspondence concerning this article should be addressed to M. Grossman, Department of Neurology-2 Gibson, Hospital of the University of Pennsylvania, 3400 Spruce Street, Philadelphia, PA 19104-4283 (e-mail: mgrossma@mail. med.upenn.edu). gated deficits in the categorization processes that $\mathrm{AD}$ patients apply to this semantic knowledge.

Models of semantic memory include at least two components: the knowledge that has been accumulated over time, and the processes that are engaged to access and use this knowledge. There is considerable evidence that patients with $A D$ are impaired on measures of semantic memory. Deficits have been documented using a wide variety of techniques, including difficulty on measures involving expression, such as confrontation naming (Bayles, Tomoeda, \& Trosset, 1990; Chan et al., 1993; Hodges, Patterson, Graham, \& Dawson, 1996; Huff, Corkin, \& Growdon, 1986; Knesevich, LaBarge, \& Edwards, 1986; Tippett, Grossman, \& Farah, 1996) and category naming (Bayles, 1982; Mickanin, Grossman, Onishi, Auriacombe, \& Clark, 1994; Monsch, Bondi, Butters, \& Paulsen, 1994; Salmon, Heindel, \& Lange, 1999), as well as on comprehension measures, such as word-picture matching (Grossman \& Mickanin, 1994; Silveri \& Leggio, 1996) and semantic priming (Albert \& Milberg, 1989; Bushell \& Martin, 
2002; Chertkow et al., 1994; Glosser, Friedman, Grugan, Lee, \& Grossman, 1998; Martin, 1992).

Perhaps the strongest work suggesting the degradation of semantic knowledge in $\mathrm{AD}$ comes from observations of a deficit for a specific category of knowledge relative to other knowledge categories, even when these are examined with the identical task (Garrard et al., 2001; Garrard, Patterson, Watson, \& Hodges, 1998; Gonnerman, Andersen, Devlin, Kempler, \& Seidenberg, 1997; Lambon Ralph, Patterson, \& Hodges, 1997; Mauri, Daum, Sartori, Riesch, \& Birbaumer, 1994; Montanes, Goldblum, \& Boller, 1995, 1996; Silveri, Daniele, Giustolisi, \& Gainotti, 1991). Some investigators have related this to degradation of the neural representation of specific features represented in modality-specific association regions of the brain (Allport, 1985; Shallice, 1988). Evidence consistent with this view comes from studies of brain-damaged patients (Damasio, Grabowski, Tranel, Hichwa, \& Damasio, 1996; Gainotti \& Silveri, 1996; Gainotti, Silveri, Daniele, \& Giustolisi, 1995; Hart \& Gordon, 1992; Hillis et al., 2001; Pietrini et al., 1988) and functional magnetic resonance imaging (fMRI) studies of healthy adults (Chao, Haxby, \& Martin, 1999; Damasio et al., 1996; Grabowski, Damasio, \& Damasio, 1998; Grossman, Koenig, et al., 2002; Martin, Wiggs, Ungerleider, \& Haxby, 1996; C. J. Moore \& Price, 1999; Perani et al., 1995; C. D. Smith et al., 2001). Others have emphasized a distributed network that does not necessarily have a focal neural representation (Devlin, Gonnerman, Andersen, \& Seidenberg, 1998; Devlin et al., 2002; McRae, de Sa, \& Seidenberg, 1997; Tippett \& Farah, 1994; Tyler \& Moss, 2001).

The second component of our hypothesized semantic memory system is the focus of the present study, in which we were concerned with the processes that AD patients engage when accessing and using semantic memory. An object is categorized with like objects in order to understand its meaning Although some have proposed a singlesystem approach (Nosofsky \& Johansen, 2000; Nosofsky \& Palmeri, 1998), we tested the hypothesis that at least two kinds of processes contribute to semantic category membership decisions about word meaning. The first kind of process involves a global comparison of a test object with remembered instances of the semantic category (Medin, Goldstone, \& Gentner, 1993; Medin \& Schaffer, 1978), or, possibly, a comparison with a mental prototype representing category members (Rosch \& Mervis, 1975; E. E. Smith \& Medin, 1981). This similarity-based semantic process is relatively rapid and appears to depend, in large part, on sensory-motor features such as the appearance of an object. A second kind of categorization process involves a more analytic, or rule-based, approach, where an object is evaluated with reference to a set of critical features (Patalano, Smith, Jonides, \& Koeppe, 2001; E. E. Smith \& Sloman, 1994). This analytic process has significant executive resource demands: The set of critical features must be kept active in working memory, where they are updated in an organized manner to keep track of the results of the rule-based process; switching allows explo- ration of the many features associated with an object; selective attention governs inspection of the object for the relevant features; and inhibitory control manages irrelevant features even if they are highly salient. It is not difficult to conceive of specific situations in which either a similarity-based or a rule-based approach to semantic categorization may be most useful, and this has prompted investigators to posit that both approaches are available to people, depending on the demands of a particular situation (Allen \& Brooks, 1991; Hampton, 1998; Rips, 1989; E. E. Smith \& Sloman, 1994).

Much experimental evidence has supported this dual approach to semantic categorization(Rips, 1989; E. E. Smith $\&$ Sloman, 1994). In these studies, subjects were given a description of an object (e.g., "a round object 2 in. in diameter") and then were asked to choose which of two available category names (in this case, "pizza" and "quarter") went best with the description. All of the descriptions included a quantitative feature that was in between the relevant dimension of the available choices (e.g., "2 in." is between the diameters of a pizza and a quarter). Moreover, one of the associated semantic categories was fixed in the relevant dimension (e.g., a quarter) and the other was variable in its relevant dimension (e.g., a pizza). The description and the two choices were presented under two conditions. The first involved a similarity judgment, where subjects decided which category bore a closer overall resemblance to the description. The second condition involved analytic or rule-based processing, since the subjects were told that only one of the choices was correct. In the latter case, the categorization process entailed identifying the category that was fixed in the relevant dimension (e.g., a quarter), understanding that this category could not meet the criterion specified in the description (e.g., a quarter by definition is fixed at a diameter that is not $2 \mathrm{in}$.), and then choosing the category that was variable on the relevant dimension (e.g., a pizza can be any diameter). Rips (1989) and E. E. Smith and Sloman (1994) demonstrated that semantic categorization decisions varied depending on the instructions. Under the rule condition in which a subject decided which one of the categories must be portrayed by the description, the subjects were more likely to choose the category that could vary on the appropriate dimension (in this case, a quarter cannot be 2 in. in diameter, so the description must be of a pizza); under the similarity condition, the dimensionality of the object description was designed so that the two types of categories were selected equally often. This pattern of findings was taken as evidence that people implement either similarity-based or rule-based processes during the categorization required to understand an object description.

The status of these categorization processes in $\mathrm{AD}$ is unclear. Studies relevant to the rule-based approach to semantic categorization have probed judgments of specific attributes associated with a word. Some work has demonstrated inaccurate judgments of the attributes of words in AD (Chertkow \& Bub, 1990; Cox, Bayles, \& Trosset, 1996; Flicker, Ferris, Crook, \& Bartus, 1987; Martin \& Fedio, 
1983); others have shown that AD patients are accurate but slow (Grober, Buschke, Kawas, \& Fuld, 1985; Nebes \& Brady, 1990; E. E. Smith, 1995). Unfortunately, stimulus features presented to patients have at times been critical to a category, whereas others have been salient but irrelevant, and these have not been distinguished from each other in any consistent fashion. Studies pertinent to similaritybased semantic categorization in AD have asked subjects to judge the typicality of various exemplars in a category. These investigations also have yielded mixed results. Some work has demonstrated relatively preserved typicality judgments, such as greater accuracy and speed for more typical exemplars of a category (Cronin-Golomb, Keane, Kokodis, Corkin, \& Growdon, 1992; Johnson \& Hermann, 1995); other studies have suggested that typicality judgments may be abnormal, particularly for less representative instances of a category (Chan et al., 1993; Grober et al., 1985; Grossman \& Mickanin, 1994). In the present study, we modified the procedure of Rips (1989) and E. E. Smith and Sloman (1994) in order to evaluate more carefully the integrity of the rule-based processes that contribute to semantic comprehension. We predicted that AD patients would be limited to using similaritybased processes during categorization challenges.

Evidence supporting the hypothesis of poor rule-based categorization in $\mathrm{AD}$ can be derived from two sources. First, many recent observations suggest that AD patients have limited executive resources (Binetti, Padovani, Cappa, Bianchetti, \& Trabucchi, 1996; Fisher, Freed, \& Corkin, 1990; LaFleche \& Albert, 1995; Pate, Margolin, Friedrich, \& Bentley, 1994; Patterson, Mack, Geldmacher, \& Whitehouse, 1996; Perry \& Hodges, 1999). We used correlations in the present study to examine the contribution of specific executive resources to rule-based semantic categorization. Several reports have attributed AD patients' impaired performance on off-line semantic measures to a nonspecific limitation of task-related resources (Nebes \& Brady, 1988, 1990; Ober \& Shenaut, 1995; Ober, Shenaut, Jagust, \& Stillman, 1991). To dissociate specific executive resources from nonspecific or overall task-related difficulty, we adopted the technique of presenting perceptually degraded stimuli (Barch, Braver, Nystrom, Forman, \& Cohen, 1997). We hypothesized that limited executive resources contribute to an impairment in rule-based aspects of semantic categorization and that rule-based categorization deficits do not depend on nonspecific task difficulty.

A second source of evidence consistent with a rulebased semantic categorization impairment in AD involves the assessment of patients with frontotemporal dementia (FTD). This is a progressive neurodegenerative condition that tends to affect frontal and anterior temporal portions of the brain (Brun \& Gustafson, 1993; Grossman, 2002; Gustafson, 1993; The Lund and Manchester Groups, 1994; McKhann et al., 2001; Neary et al., 1998; Snowden, Neary, $\&$ Mann, 1996). These patients do not have prominent episodic memory deficits early in the course of their disease, although they are compromised in their performance on several other cognitive and behavioral domains. Some of these patients - the subgroup of FTD patients with semantic dementia - appear to have a progressive form of aphasia that is associated with an obvious impairment of semantic memory and lexical retrieval (Hodges \& Patterson, 1996; Hodges et al., 1999; Lambon Ralph, McClelland, Patterson, Galton, \& Hodges, 2001; Murre, Graham, $\&$ Hodges, 2001; Snowden, 1999). Another subgroup of FTD patients has a nonfluent form of progressive aphasia that is associated with effortful speech and grammatical comprehension difficulty (Grossman, Mickanin, et al., 1996; Snowden, Neary, Mann, Goulding, \& Testa, 1992). Other FTD patients have executive resource deficits and a disorder of social comportment without an obvious aphasia (Elfgren, Passant, \& Risberg, 1993; Pasquier, Lebert, Grymonprez, \& Petit, 1995; Rahman, Sahakian, Hodges, Rogers, \& Robbins, 1999). Progressive nonfluent aphasic and executive/behavioral subgroups of FTD patients are generally superior to AD patients in their lexical comprehension (Grossman, D'Esposito, et al., 1996; Grossman, Mickanin, et al., 1996). However, detailed analyses of error patterns suggest deficits even in these FTD patients on probes of single-word comprehension (Koenig, Smith, Dennis, et al., 2002; Koenig, Smith, Moore, Dennis, \& Grossman, 2002; P. Moore, Dennis, McMillan, \& Grossman, 2002), suggesting a role for executive resources in decisions about single-word meaning. Support for this possibility comes from functional neuroimaging studies of word meaning that have implicated portions of the frontal cortex in decisions about single-word meaning (Demb et al., 1995; Demonet et al., 1992; Grossman, Smith, et al., 2002; Kapur et al., 1994; Petersen, Fox, Posner, Mintum, \& Raichle, 1989; Poldrack et al., 1999; Raichle et al., 1994; Thompson-Schill, D’Esposito, Aguirre, \& Farah, 1997; Tulving, Kapur, Craik, Moscovitch, \& Houle, 1994). We predicted that the rule-based processing deficit in AD patients' semantic categorization difficulty would resemble the rule-based semantic processing deficit in FTD patients.

\section{METHOD}

\section{Subjects}

We assessed 23 right-handed native English speakers who were diagnosed with probable dementia of the Alzheimer's type (AD), according to National Institute of Neurological and Communicative Diseases and Stroke-Alzheimer's Disease and Related Disorders Association criteria (McKhann et al., 1984). These patients were recruited from the Department of Neurology at the Hospital of the University of Pennsylvania. AD patients were screened for severity of dementia, and participation was restricted to mildly and moderately impaired patients according to the Mini-Mental State Exam (MMSE; Folstein, Folstein, \& McHugh, 1975). ${ }^{1}$ We identified patients so that they matched the MMSE of FTD patients (see below). On the basis of a comprehensive medical history and review of systems, a structured neurologic exam, serum studies, structural imaging studies with MRI, and functional neuroimaging studies with SPECT or PET, we excluded patients with other causes of dementia (such as vascular disease or hydrocephalus), psychiatric disorders (such as primary depression or psychosis), medical illnesses or metabolic conditions that may have resulted in encephalopathy, in- 
fectious diseases that may have resulted in progressive intellectual decline, and/or other medical conditions that may have an impact on cognitive performance. None of the subjects was taking sedating medications at the time of testing.

We also studied 17 patients with FTD, identified in the out-patient clinic at the Department of Neurology of the University of Pennsylvania according to a modified version of the Lund-Manchester criteria (The Lund and Manchester Groups, 1994; McKhann et al., 2001). Briefly, these right-handed native English speakers exhibited features of progressive cognitive and/or behavioral decline involving impairments in language, planning, and social comportment that limited their ability to sustain complex activities, such as maintaining a job or managing a household, despite relatively preserved episodic memory functioning early in the course of the disease. As with the AD patients, a comprehensive medical history, a review of systems, a structured neurologic exam, serum studies, structural imaging studies with MRI, and functional neuroimaging studies with SPECT or PET were used to exclude patients with other causes of dementia (such as vascular disease or hydrocephalus), psychiatric disorders (such as primary depression or psychosis), medical illnesses or metabolic conditions that may have resulted in encephalopathy, infectious diseases that may have resulted in progressive intellectual decline, and/or other medical conditions that may have an impact on cognitive performance. We subgrouped FTD patients clinically on the basis of criteria described by Neary et al. (1998), as modified more recently during a reliability assessment (Davis, Price, Moore, Campea, \& Grossman, 2001; Price, Davis, Moore, Campea, \& Grossman, 2001). These subgroups included progressive nonfluent aphasia $(n=6$; effortful, agrammatic spontaneous speech that may be dysarthric, associated with naming difficulty), semantic dementia ( $n=6$; fluent, circumlocutory spontaneous speech with impaired single-word comprehension), and dysexecutive and behavioral disorder $(n=5$; impaired executive functioning and disordered social comportment with relatively preserved speech). Consensus subgrouping was achieved through independent review of a semistructured medical history, mental status examination, and neurological examination of each FTD patient by two or more trained reviewers. If subgrouping agreement was not achieved, a consensus discussion resolved differences. The AD patients and the FTD patients were matched in their overall dementia severity, according to the MMSE $[t(38)=0.42$, n.s.]. The subjects were not taking any sedating medications at the time of testing, although several of the patients were taking small doses of a serotonin-specif ic reuptake inhibitor, a dopaminergic agonist, or a neuroleptic agent.
These patients were compared with 31 healthy seniors who were right-handed native English speakers. The healthy control subjects were matched with the patients for age $[\mathrm{AD}, t(52)=1.68$, n.s.; FTD, $t(46)=1.95$, n.s. $]$ and education $[\mathrm{AD}, t(52)=1.73$, n.s.; FTD, $t(46)=$ 1.22 , n.s.]. Pilot work showed that healthy control subjects are able to recall the learning conditions over 1 month, so contamination effects were avoided by asking each of the control subjects to participate in only one of the three conditions (see below). Assignment to a condition was random. The control subjects were then assembled into roughly 10 pseudosubjects for statistical comparison with the $\mathrm{AD}$ and the FTD patients.

Demographic features of the patients and the healthy control subjects are summarized in Table 1 . We also summarize in Table 1 performance on neuropsychological measures of semantic memory, episodic memory, and executive functioning administered to the patients in a different session conducted within 3 months of the categorization procedure. $Z$ scores based on 25 age- and educationmatched control subjects are provided. We report the following measures.

Episodic memory (Welsh, Butters, Hughes, Mohs, \& Heyman, 1991). Patients repeated an aurally presented list of 10 one-syllable and two-syllable nouns on three successive trials. Following a brief filled period, during which another task was performed, patients were asked to recall the words and then recognize the target words intermixed with an equal number of foils. We report the number of correctly recalled words following a filled delay.

Semantic association (Howard \& Patterson, 1992). On the Pyramid and Palm Tree Test, the subjects decided which of two available choices was more closely associated with a target stimulus. We administered both word triads and picture triads and we report accuracy averaged across both materials.

Visual confrontation naming (Kaplan, Goodglass, \& Weintraub, 1983). We administered an abbreviated version of the Boston Naming Test. This involved confrontation naming of visual line drawings of objects. We report naming accuracy.

Category naming fluency (Mickanin et al., 1994). This measure of lexical semantic retrieval also involves mental organization and working memory. The subjects named as many different animals as possible in $60 \mathrm{sec}$. We report the total number of unique names that are animals.

Letter fluency (Mickanin et al., 1994). In this measure of mental search, the subjects named as many different words as possible beginning with the letters $\mathrm{F}, \mathrm{A}$, and $\mathrm{S}$. They were given 1 min to name words beginning with each letter and were told not to provide proper

Table 1

Mean $( \pm S D)$ Demographic Features and Neuropsychological Performance of Control Subjects, Alzheimer's Disease Patients, and Frontotemporal Dementia Patients

\begin{tabular}{|c|c|c|c|c|c|c|}
\hline & \multicolumn{2}{|c|}{$\begin{array}{l}\text { Healthy Seniors } \\
\quad(n=31) \\
\end{array}$} & \multicolumn{2}{|c|}{$\begin{array}{l}\text { Alzheimer's Patients } \\
\quad(n=23) \\
\end{array}$} & \multicolumn{2}{|c|}{$\begin{array}{c}\text { Frontotemporal } \\
\text { Patients } \\
(n=17) \\
\end{array}$} \\
\hline & $M$ & $S D$ & $M$ & $S D$ & $M$ & $S D$ \\
\hline Age (years) & 68.6 & 7.9 & 72.1 & 7.0 & 63.3 & 10.7 \\
\hline Education (years) & 16.3 & 4.4 & 14.5 & 2.5 & 14.7 & 2.9 \\
\hline $\operatorname{MMSE}(\operatorname{maximum}=30)$ & \multicolumn{2}{|c|}{-} & 22.3 & 4.4 & 23.0 & 6.1 \\
\hline Episodic memory & \multicolumn{2}{|c|}{-} & -2.08 & 0.3 & -1.56 & 0.9 \\
\hline Semantic association & \multicolumn{2}{|c|}{-} & -2.16 & 3.4 & -6.73 & 7.6 \\
\hline Confrontation naming & \multicolumn{2}{|c|}{-} & -6.72 & 6.5 & -6.82 & 7.6 \\
\hline Category naming & \multicolumn{2}{|c|}{-} & -1.72 & 0.9 & -2.82 & 0.9 \\
\hline Letter fluency & \multicolumn{2}{|c|}{-} & -0.63 & 0.7 & -2.03 & 0.9 \\
\hline Trails B & \multicolumn{2}{|c|}{-} & -2.98 & 1.8 & -2.56 & 2.1 \\
\hline Stroop & \multicolumn{2}{|c|}{-} & -8.17 & 10.8 & -6.72 & 11.9 \\
\hline Digit span-reverse & \multicolumn{2}{|c|}{-} & -0.47 & 0.9 & -1.42 & 0.8 \\
\hline
\end{tabular}

Note-Patients' neuropsychological performance was quantified as $z$ scores relative to 25 age- and education-matched healthy seniors. MMSE, Mini-Mental State Exam. 
names or numbers. We report the average number of words named per minute.

Stroop test (Stroop, 1935). In this measure of inhibitory control, the subjects were shown a sheet of paper containing five columns of 16 color names printed in a colored font that differed from the word (e.g., the word RED printed in a green font). The subjects named as many of the font colors as possible. We report the total number of errors made by the patients during task performance (up to $300 \mathrm{sec}$ ).

Trails B test (Reitan, 1958). In this measure of task switching, the subjects were shown a sheet of paper with randomly arrayed numbers (1 to 13) and letters (A to M). They were asked to join the letters and numbers in ascending order, alternating between letters and numbers (i.e., " $1-\mathrm{A}-2-\mathrm{B}-3-\mathrm{C}$..."). We report the amount of time (up to $300 \mathrm{sec}$ ) needed by the subjects to complete the task.

Digit span-reverse (Wechsler, 1995). To assess working memory, the subjects repeated increasingly longer lists of numbers in an order that reversed the order of presentation. We report the longest set of digits that the subjects repeated correctly in the reverse order.

Using a $z$ score of -1.65 as the threshold for a significant abnormality, we found that the AD and the FTD patients were significantly impaired on measures requiring semantic memory, including semantic association, confrontation naming, and category naming. The AD patients were also impaired on a measure of episodic memory, and both groups were impaired on several measures of executive functioning (see Table 1).

\section{Materials}

We developed 20 brief written descriptions of objects. Each included a quantitative measure of one feature, such as "a round object 2 in. in diameter." The subjects were asked to select which of two available written category names best captured the described object. The quantitative value was selected so that it was intermediate in its extent between the two categories. Pretesting in 10 young control subjects helped determine the quantity that would lead to the association of the object description to each category roughly half of the time. Moreover, the relevant dimension was fixed in its dimensionality for one of the two available categories and was variable for the second category. The description "a round object 2 in. in diameter," for example, was presented with "quarter" (a category that has a fixed diameter smaller than 2 in.) and "pizza" (a category with a variable diameter that is generally larger than 2 in. but need not be). The fixed and variable choices were matched in their frequencies of occurrence (Francis \& Kučera, 1982).

We also administered 20 rich descriptions to the subjects. These were identical to the brief descriptions, except that the descriptions included an additional phrase that is characteristically associated with the fixed categories. For example, a rich description might be "a round object 2 in. in diameter found in an arcade." A quarter is often found in an arcade, although this is clearly not a necessary feature of "quarter." A pizza can be found in an arcade as well, although this association is not as strong as it is for quarters (according to assessments of 5 young subjects).

We assessed the patients' knowledge of the dimensions of the categories used in this study by asking them to evaluate the truth value of 80 statements. Half of the statements about each category were true (e.g., "A quarter is 1 in. in diameter"), and half were false (e.g., "A quarter is 3 in. in diameter"). The statements were presented aurally to the patients in a random order at the completion of the protocol.

The description and the two category choices were presented to the subjects under two experimental conditions. In the first, rule condition, the subjects were told that one of the choices must be correct and that the choices should be carefully considered in the context of the description. The subjects were encouraged to "think aloud," since a previous experiment had shown that responses under the rule condition were more likely to be appropriate if the subjects explicitly reasoned about the nature of the description relative to the properties of the available category choices (E. E. Smith \& Sloman,
1994). In the case of the rich descriptions, moreover, consideration of the irrelevant feature associated with the fixed object must be inhibited so that the correct answer can be identified. The second, similarity condition required the subjects to choose the category that had the greatest overall similarity to the description. The subjects were told that there was no correct answer and that they had to decide which category was most similar, overall, to the description. All but 2 of the 23 AD patients and all of the FTD patients participated in both the rule and the similarity conditions, with randomly ordered sessions separated by about 1 month.

We also administered a control, or degraded, condition. This was identical to the similarity condition, except that the font for presenting the written object description and the written category choices was perceptually degraded. This condition was administered because of the likelihood that the rule condition would be more demanding than the similarity condition. We sought to make the similarity condition as demanding, in a general or overall sense, as the rule condition, but without requiring specific executive resources and without provoking a rule-like attitude when considering the descriptions, paralleling Barch et al. (1997). This control condition was used to help us establish more confidently the role of specific executive resources during rule-based categorization by dissociating nonspecific task difficulty. We established the degree of perceptual degradation empirically with 5 young subjects and 5 older subjects in such a way that the latencies to respond to these problems was prolonged so as to approximate the latencies needed to make decisions in the rule condition. Subgroups of 17 AD patients and 11 FTD patients participated in the degraded condition.

\section{Procedure}

These problems were presented by laptop computer (Macintosh G3) controlled by Psyscope software (Cohen, MacWhinney, Flatt, \& Provost, 1993). First, the subjects saw the written description for $4 \mathrm{sec}$, and then the two written category choices were also made available, arrayed horizontally beneath the description on the computer screen. The variable category choice was in the left position for $50 \%$ of the trials, the fixed choice was in the left position for the remaining trials, and these types of items were ordered pseudorandomly so that the category with the variable feature was in the same lateralized position for no more than three consecutive trials. The subjects pressed one of two computer keys (one on the left of the keyboard beneath the display, the other on the right) to indicate their selection. The descriptions were presented in two blocks, with a brief rest in between the blocks. Half of the brief descriptions and half of the rich descriptions were in one block. The second block consisted of rich versions of the brief descriptions presented in the first block and brief versions of the rich descriptions presented in the first block. The order of block presentation was random. The items of interest were mixed with an equal number of similarly structured trials that included a description and two choices, where neither object was fixed in the dimension mentioned in the description.

Each session consisted of the presentation of these descriptions only under rule, similarity, or similarity-degraded conditions. Each of the sessions was separated by at least a month from the others. The order of condition presentation was random. Healthy subjects were exposed to only one condition. Prior to each session, the subjects were given a training session that familiarized them with the instructions and the experimental apparatus, including the presentation of several practice trials. All the subjects appeared to understand the procedure.

\section{RESULTS}

\section{Categorization in Control Subjects}

For brief descriptions, $t$ tests demonstrated that the healthy seniors were significantly more likely to select the variable 


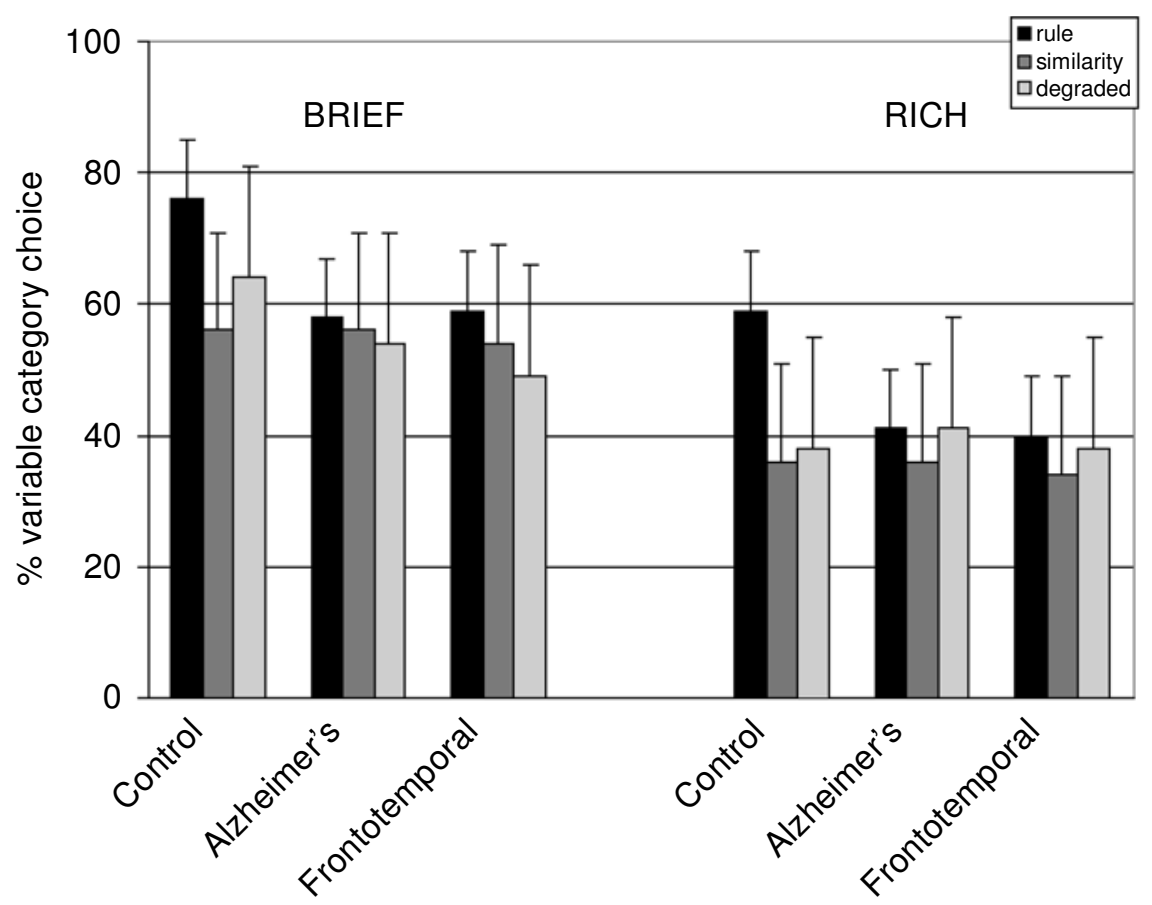

Figure 1. Mean $( \pm S D)$ percentages of selection of the variable category under rule, similarity, and similarity-degraded conditions in healthy seniors, Alzheimer's patients, and frontotemporal dementia patients.

category under rule instructions than under similarity instructions $[t(9)=3.90, p<.005]$, as is illustrated in Figure 1 . Thus, the healthy control subjects were able to identify the category with the fixed relevant dimension and then reject this category since it did not meet the criterion in the description. This is unlikely to have been due to nonspecific difficulty associated with the rule condition, since the healthy control subjects also selected the variable category significantly more often under rule instructions than under similarity instructions with perceptually degraded presentations $[t(9)=2.43, p<.05]$. The control subjects were not more likely to select the variable category under similarity instructions with clearly printed text, as compared with the similarity-degraded condition $[t(9)=2.17$, n.s. $]$. These findings replicated the results of previous assessments of categorization, with a paradigm similar to this, in young adults (Rips, 1989; E. E. Smith \& Sloman, 1994).

The distinct performance profile under rule instructions was also seen for rich descriptions. The healthy seniors again selected the variable category significantly more often under rule instructions than under similarity instructions $[t(9)=3.84, p<.005]$. The control subjects thus were sensitive to the relevant feature critical to meeting the criterion specified in the description under rule instructions, as compared with similarity instructions, despite the presence of a distracting incidental feature. The healthy seniors also selected the variable category significantly more often under rule instructions, as compared with the similarity-degraded condition $[t(9)=5.34, p<.001]$, but there was no difference in selecting the variable category under similarity instructions with clearly printed text, as compared with perceptually degraded text $[t(9)=0.18$, n.s.]. In sum, these findings indicated that healthy seniors are sensitive to the critical features of categories when required to engage rule-based processes during categorization decisions about word meaning but change in their treatment of these categories when judging category membership on the basis of overall similarity.

The control subjects also showed consistent differences between brief descriptions and rich descriptions under all the instruction conditions. This included rule $[t(9)=2.76$, $p<.05]$, similarity $[t(9)=4.92, p<.001]$, and degradedsimilarity $[t(9)=9.00, p<.001]$ conditions. The healthy control subjects thus consistently categorized rich descriptions into the variable category significantly less often than brief descriptions. This emphasizes that these subjects were sensitive to the incidental features of rich descriptions that were designed to bias subjects away from the variable category. Despite the biases associated with the irrelevant features of the rich descriptions, the healthy seniors were able to implement rule-based criteria based on detecting the feature critical for category membership, as was noted above.

\section{Categorization in Alzheimer's disease}

Unlike the control subjects, the patients with AD did not differ in their categorization performance under rule instructions, as compared with similarity instructions. As is summarized in Figure 1, this was true for brief descriptions 
$[t(20)=0.70$, n.s. $]$ and rich descriptions $[t(20)=1.30$, n.s.]. Under the rule condition, direct comparisons showed that the AD patients differed from the control subjects for brief descriptions $[t(29)=3.31, p<.005]$ and rich descriptions $[t(29)=2.72, p<.01]$. In both cases, the effect size was on the order of $20 \%$. However, the AD patients did not differ from the control subjects in their selection of a category under similarity instructions for brief descriptions $[t(32)=0.07$, n.s. $]$ and rich descriptions $[t(32)=0.13$, n.s.]. The difference between the healthy seniors and the $\mathrm{AD}$ patients under the rule condition cannot be attributed to degraded knowledge of the categories in semantic memory, since the AD patients $(92.3 \%$ [ $\pm 8.3 \%]$ correct) were as accurate as the control subjects $(94.3 \%$ [ $\pm 3.3 \%)$ correct] and the FTD patients $[87.1 \%( \pm 12.9 \%)$ correct] in their truth value judgments of statements about the dimensionality of the categories, as assessed by a Kruskal-Wallis test, because of possible nonnormal distributions associated with ceiling effects $\left[\chi^{2}(2)=4.4\right.$, n.s.]. These findings imply that AD patients are less sensitive than control subjects to the critical features of categories under rule-based instructions but do not differ from control subjects in their similarity-based judgments.

We examined performance with perceptually degraded stimuli under similarity instructions in AD to determine whether general or overall difficulty would account for their performance limitations with rule-based categorization. We found that categorization performance under similarity instructions with perceptually degraded material did not differ from performance under similarity instructions with clear text [brief descriptions, $t(13)=0.74$, n.s.; rich descriptions, $t(13)=0.99$, n.s.] and differed only marginally as compared with rule-based instructions [brief descriptions, $t(13)=2.16, p<.05$; rich descriptions, $t(13)=1.34$, n.s.]. Thus, increasing overall task-related difficulty by degrading stimulus materials perceptually does not result in a major decrement in AD patients' performance and appears to have minimal impact on rulebased categorization.

It is important to note that the AD patients were not indiscriminately insensitive to all features of objects. Specifically, like the control subjects, the AD patients were biased away from choosing the variable category for a rich description, as compared with a brief description. This was evident under rule instructions $[t(20)=7.73, p<$ $.001]$ and similarity instructions $[t(22)=7.61, p<.001]$ and in the degraded-similarity condition $[t(16)=3.14$, $p<.01]$. Thus, the AD patients and the control subjects were equally sensitive to the bias induced by the incidental features of rich descriptions, implying that $\mathrm{AD}$ patients have selective difficulty isolating the features of a category that are critical during rule-based categorization.

\section{The Role of Executive Resources and Episodic Memory in AD Patients' Categorization}

Several observations suggest that $\mathrm{AD}$ patients' poor rulebased processing is related to a limitation in the executive resources needed for this form of categorization - specifically, to attend selectively to one feature while inhibiting others. First, we examined correlations between categorization and performance on measures of executive functioning. Our summary measure for categorization was the difference in the percentage of choosing the variable category during the rule condition minus the percentage of choosing the variable category during the similarity condition, averaged over brief and rich descriptions. We found that this summary measure correlated significantly with letter fluency, a measure of mental search $[r=.58, p<$ $.01]$. The summary categorization measure also correlated with Stroop performance, a measure of inhibitory control $[r=-.52, p<.02]$. We did not find a correlation between our summary measure of categorization and Trails B performance $[r=-.32$, n.s.], suggesting that the switching component central to the Trails B task contributes less importantly to rule-based categorization of object descriptions. Similarly, there was no correlation between the summary categorization measure and the reverse digit span measure $[r=.02$, n.s.], suggesting that limited working memory does not contribute substantially to semantic categorization difficulty. When we correlated categorization with MMSE and episodic memory performance, we did not find a correlation $[r=.27$ and .20 , respectively], suggesting that rule-based categorization is related to specific executive resources, rather than to overall dementia severity or episodic memory.

\section{Categorization in Frontotemporal Dementia}

To test the hypothesis that difficulty with rule-based categorization is related to AD patients' executive limitations from another perspective, we examined FTD patients who were known to have significant deficits on measures of executive functioning. We found a pattern of performance in the FTD patients that closely resembled our observations of the AD patients. These findings are summarized in Figure 1. The FTD patients, like the AD patients, differed from the control subjects, since the FTD patients were equally likely to select the variable category under rulebased and similarity instructions for brief descriptions $[t(16)=1.36$, n.s. $]$ and for rich descriptions $[t(16)=$ 2.04, n.s.]. Direct comparison of the FTD patients and the AD patients with $t$ tests revealed no statistical differences between these patient groups under any condition (all $p$ values > .10). Similarly, there was no difference in the FTD patients' selection of the variable category for the degradedsimilarity condition for brief descriptions [as compared with the rule-based condition, $t(10)=1.52$, n.s.; as compared with the similarity condition, $t(10)=0.69$, n.s.] and for rich descriptions [as compared with the rule-based condition, $t(10)=1.32$, n.s.; as compared with the similarity condition, $t(10)=0.06$, n.s.]. We also divided the FTD patients into subgroups, including progressive nonfluent aphasics $(n=6)$, semantic dementia patients $(n=6)$, and patients with combined dysexecutive and social/behavioral disorder $(n=5)$. Statistical tests did not reveal any differences between these subgroups for any set of conditions. 
This suggests that the FTD patient subgroups were equally compromised in their ability to engage rule-based processes during categorization decisions. The FTD patients also were as biased as the $\mathrm{AD}$ patients and the control subjects by the incidental features of rich descriptions during their categorization judgments. Thus, like the control subjects and the AD patients, the FTD patients were biased away from the variable category for a rich description, as compared with a brief description, under rule-based instructions $[t(16)=5.21, p<.001]$ and similarity instructions with clear text $[t(16)=3.65, p<.005]$ and in degradedsimilarity conditions $[t(10)=3.70, p<.005]$. Taken together, the parallel patterns of performance across the AD patients and the FTD patients suggest that rule-based categorization impairments in $\mathrm{AD}$ are due, at least in part, to limited executive resources.

\section{DISCUSSION}

\section{Semantic Categorization in Healthy Seniors}

Our observations imply that healthy seniors engage at least two distinct processes during their categorization decisions. They are able to make overall similarity comparisons, and when obliged to, they are able to use a rule-based approach that requires selectively attending to a feature that is critical for category membership while inhibiting attention to an incidental feature. This extends to healthy seniors previous observations of categorization flexibility shown by younger subjects (Hampton, 1998; Rips, 1989; E. E. Smith \& Sloman, 1994) and emphasizes that multiple categorization processes are available to healthy subjects in an age-invariant manner.

We also found that making the similarity judgment more difficult in an overall manner by perceptually degrading the stimuli does not change the pattern of categorization performance: Rule-based instructions continue to result in significantly greater sensitivity to the critical feature of a category, relative to similarity-based judgments for perceptually degraded stimuli. Moreover, patterns of performance under similarity-based instructions do not vary depending on whether the stimuli are perceptually degraded or not. Nonspecific difficulty thus does not appear to exert a significant impact on performance, and performance changes as a result of the rule-based instructions cannot be attributed to vaguely increased task-related demands.

A final point is that healthy seniors are able to discriminate between critical features of an object and incidental features: Despite a rich description of an object containing an incidental feature that could potentially distract the subjects, the healthy seniors remained sensitive to the critical feature of a description that determined its category membership.

\section{Sematic Categorization in Alzheimer's Disease}

Consider AD patients' semantic categorization performance in this context. AD patients do not demonstrate the same flexible access to multiple categorization processes. They are able to make similarity-based categorization de- cisions in a manner that resembles healthy seniors to a remarkable extent. However, AD patients do not modify their category membership decisions when instructed to use rule-based processes: When required to identify a critical feature of a category, they continue to perform as if they are making their category membership decisions on the basis of an overall similarity-based evaluation.

It is important to point out that AD patients, like control subjects, modify their performance for rich descriptions: $\mathrm{AD}$ patients are as biased as control subjects by this additional, incidental feature. Observations of sensitivity to features in object descriptions such as this discount claims that $\mathrm{AD}$ patients' performance is chance or random. Additional evidence contradicting the claim that $\mathrm{AD}$ patients' similarity-based categorization performance is random comes from a recent study showing that $\mathrm{AD}$ patients learned to identify members of a new meaningful category under similarity-based instructions with about $72 \%$ accuracy and learned to reject nonmembers of the new category with about $79 \%$ accuracy (Koenig, Smith, Moore, et al., 2002). Furthermore, the patients' relatively preserved knowledge of the value on the critical dimension of the categories used in this study makes it less likely that degraded knowledge in semantic memory can explain their difficulty. Thus, it appears that it is the status of a feature as critical to a category that is the source of difficulty for $\mathrm{AD}$ patients under rule-based instructions. These findings are consistent with the hypothesis that a crucial process central to word meaning - the process of rule-based categorization -is compromised in AD.

Some investigators hypothesize that a single system can explain the performance seen in the kind of experiment described above (Nosofsky \& Johansen, 2000; Nosofsky $\&$ Palmeri, 1998). From this perspective, the rule-based impairment in AD may be due to limitations in dimensional weighting and context sensitivity, which are important properties of the psychological similarity space in which object descriptions are embedded. The inclusion, in our experiment, of brief versus rich object descriptions as a factor orthogonal to rule-based and similarity-based categorization in fact tests characteristics such as context sensitivity by requiring patients to narrow the distribution of object features for comparison with an exemplar. We found that $\mathrm{AD}$ patients are as sensitive as healthy seniors to the biasing effects of a rich description. Yet AD patients are significantly less sensitive than healthy seniors to the rule-based nature of some categorization instructions. This dissociation is consistent with the dual approach to categorization.

We hypothesize that the rule-based process for semantic categorization depends in part on executive resources, such as selective attention, inhibitory control, working memory, and switching. These are needed to select the list of features under evaluation for their critical status, to maintain inhibitory control over irrelevant features that can obscure the important role of critical features during rule-based semantic categorization, and to support switching between features during inspection of an object. AD 
patients are known to have executive resource limitations (Fisher et al., 1990; LaFleche \& Albert, 1995; Pate et al., 1994; Patterson et al., 1996; Perry \& Hodges, 1999). Other work has demonstrated that these executive difficulties detract from AD patients' performance on language tasks (Grossman \& Rhee, 2001; Kempler, Almor, Tyler, Andersen, \& MacDonald, 1998; Kempler, Andersen, \& Henderson, 1995; Waters \& Caplan, 1997; Waters, Rochon, \& Caplan, 1998). We assessed the hypothesized role of executive resources in rule-based semantic categorization from two perspectives. First, we correlated AD patients' rule-based categorization with measures of executive functioning. We found that performance on rule-based categorization judgments correlated with performance on several specific measures of executive functioning. This included letter fluency and Stroop performance. The selective nature of the correlation pattern suggests that executive resources are not undifferentiated but may make selective contributions to semantic categorization. Although this correlational approach has many limitations, these observations are consistent with the claim that impaired executive functioning contributes to AD patients' difficulty with rule-based semantic categorization.

We implemented a control condition, using perceptually degraded stimuli to assess the possibility that the $\mathrm{AD}$ patients were impaired due to nonspecific task-related difficulty. We did not observe a frank decrement in performance with perceptually degraded stimuli. This approach was used previously to make a task more difficult without necessarily requiring the implementation of specific executive resources, such as working memory (Barch et al., 1997). In this fMRI study, the distribution of cortical activation associated with a working memory task was uninfluenced by performance on a condition that was made more difficult in a nonspecific fashion by the perceptual degradation of the stimuli. Some AD patients have visual perceptual impairments (Cronin-Golomb et al., 1991; Levine, Lee, \& Fisher, 1993; Mendez, Mendez, Martin, Smyth, \& Whitehouse, 1990; Ober, Jagust, Koss, Delis, \& Friedland, 1991; Sadun, Borchert, DeVita, Hinton, \& Bassi, 1987), and this kind of deficit can impact performance on language measures, such as naming and wordpicture matching (Silveri \& Leggio, 1996; Tippett \& Farah, 1994). From this perspective, it is possible that the degradation of visual stimuli would tax executive resources more directly by requiring $\mathrm{AD}$ patients to retain partially processed material in working memory during the prolonged period needed to process the stimuli. We would have expected a performance decrement during similarity-based categorization for degraded stimuli, relative to nondegraded stimuli. However, this was not observed. These findings suggest that accounts appealing to nonspecific difficulty cannot easily explain AD patients' pattern of impaired semantic categorization. Rule-based categorization nevertheless may involve some general problem solving, in that subjects must make a categorization decision on the basis of something like a process of elimination (e.g., "it's too wide to be a quarter; therefore, it must be the other alternative"). Additional work is needed to assess the role of problem-solving in rule-based categorization.

The second way that we assessed the role of executive functioning in rule-based semantic categorization was to evaluate FTD patients. Patients with FTD are known to have limited executive resources (Elfgren et al., 1993; Pasquier et al., 1995; Rahman et al., 1999). We found a remarkable resemblance between AD patients and FTD patients: These groups of subjects were equally limited in their ability to engage rule-based semantic categorization. To be sure, we cannot rule out the possibility that AD patients and FTD patients are impaired for different reasons on this task, and additional work is necessary to help define the similarities and differences across these two groups of patients.

Intact functioning of executive resources is said to depend, in large part, on the integrity of the prefrontal cortices. A large body of work has emphasized the critical role of prefrontal brain regions in the performance of executive measures (E. E. Smith \& Jonides, 1999; E. E. Smith, Marshuetz, \& Geva, 2002). More recently, several studies have demonstrated the contribution of frontal recruitment during assessments of semantic memory (Demb et al., 1995; Demonet et al., 1992; Grossman, Smith, et al., 2002; Kapur et al., 1994; Petersen et al., 1989; Poldrack et al., 1999; Raichle et al., 1994; Tulving et al., 1994). In a functional neuroimaging study of healthy adults, for example, Thompson-Schill et al. (1997) tested the hypothesis that inferior frontal activation during semantic tasks is related to the process of selecting a relevant feature of semantic knowledge from a set of competing alternatives. Three tasks were administered to the same set of subjects under two conditions: High selection (in which alternatives were equally strong) and low selection (in which one alternative was dominant). The investigators reported increased activation centered in Brodmann area 44/45 for the highselection condition, as compared with the low-selection condition, of each task. Although this report described frontal activation in a study assessing an executive resource such as selective attention in semantic memory, the difference between high selection and low selection does not correspond to the difference between rule-based and similarity-based categorization examined in the present study. In another study directly contrasting rule-based and similarity-based categorization, Grossman, Smith, et al. (2002) presented the object descriptions used in the present study to young healthy adults while monitoring regional cerebral activity with $\mathrm{fMRI}$. The subjects then categorized these descriptions, using rule-based or similarity-based instructions. Behavioral performance was very similar to that observed in the healthy seniors of the present study: The subjects demonstrated their access to multiple categorization strategies through differences in performance that depended on the use of either similarity-based or rulebased instructions. A direct contrast of rule-based categorization and similarity-based categorization showed greater activation of the left dorsolateral prefrontal cortex 
(Brodmann areas 8 and 9) for rule-based categorization. In a recent fMRI study of semantic memory in $A D$, there was reduced activation of the lateral prefrontal cortex (Brodmann areas 44 and 46) during probes of word meaning across multiple semantic categories (Grossman et al., 2003). These observations are consistent with the hypothesis that AD patients' poor rule-based categorization is due, at least in part, to a limitation in executive resources supported by prefrontal brain regions.

We used two-tailed $t$ tests to examine our data statistically. Our statistical tests were determined in an a priori manner guided by our hypothesis. Despite the availability of small groups in patient-based studies such as this, we found consistent statistical support for our hypothesis. We did not correct for multiple comparisons in our statistical tests because of the hypothesis-driven nature of our analysis and because many of these tests were used to assess control conditions (e.g., judgments of degraded stimuli and assessments of FTD patients) implemented to bolster the validity of our claims.

In sum, we found that rule-based semantic categorization is limited in patients with AD. This observation begins to suggest that the semantic memory impairment in $\mathrm{AD}$ is due to several kinds of difficulty. There may be degradation of semantic knowledge in these patients, possibly affecting their comprehension for a specific category of knowledge. On the basis of our observations, AD patients' semantic memory deficit also may be due in part to an impairment appreciating the significance of a category's critical features, while inhibiting its incidental features, during rule-based semantic categorization judgments.

\section{REFERENCES}

Albert, M. S., \& Milberg, W. (1989). Semantic processing in patients with Alzheimer's disease. Brain \& Language, 37, 163-167.

Allen, S. W., \& Brooks, L. R. (1991). Specializing the operation of an explicit rule. Journal of Experimental Psychology: General, 120, 3-17.

Allport, D. A. (1985). Distributed memory, modular subsystems and dysphasia. In S. K. Newman \& R. Epstein (Eds.), Current perspectives in dysphasia (pp. 32-60). Edinburgh: Churchill Livingstone.

Barch, D. M., Braver, T. S., Ny st rom, L. E., Forman, S. D., \& Cohen, J. D. (1997). Dissociating working memory from task difficulty in human prefrontal cortex. Neuropsychologia, 35, 1373-1380.

BAYLES, K. A. (1982). Language function in senile dementia. Brain \& Language, 16, 265-280.

Bayles, K. A., Tomoeda, C. K., \& Trosset, M. W. (1990). Naming and categorical knowledge in Alzheimer's disease: The process of semantic memory deterioration. Brain \& Language, 39, 498-510.

Binetti, G., Padovani, A., Cappa, S. F., Bianchetti, A., \& TrabucCHI, M. (1996). Executive function in early Alzheimer disease. Journal of Neurology, Neurosurgery, \& Psychiatry, 60, 91-93.

BRUN, A. \& GUSTAFSON, L. (1993). The Lund longitudinaldementia study: A 25 year perspective on neuropathology, differential diagnosis, and treatment. In B. Corain, K. Iqbal, M. Nicolini, B. Winblad, H. Wisniewski, \& P. Zatta (Eds.), Alzheimer's disease: Advances in clinical and basic research (pp. 3-18). London: Wiley.

Bushell, C., \& Martin, A. (2002). Automatic semantic priming of nouns and verbs in patients with Alzheimer's disease. Neuropsychologia, 35, 1059-1067.

Chan, A. S., Butters, N., Paulsen, J. S., Salmon, D. P., Swenson, M. R., \& Maloney,L. T. (1993). An assessment of the semantic network in patients with Alzheimer's disease. Journal of Cognitive Neuroscience, 5, 254-261.
Chan, A. S., Salmon, D. P., Butters, N., \& Johnson, S. A. (1995). Semantic network abnormality predicts rate of cognitive decline in patients with probable Alzheimer's disease. Journal of the International Neuropsychological Society, 1, 297-303.

Chao, L. L., Haxby, J., \& Martin, A. (1999). Attribute-based neural substrates in temporal cortex for perceiving and knowing about objects. Nature Neuroscience, 2, 913-919.

Chertkow, H., \& Bub, D. N. (1990). Semantic memory loss in dementia of the Alzheimer's type: What do the various measures measure? Brain, 113, 397-417.

Chertkow, H., Bub, D., Bergman, H., Bruemmer, A., Merling, A., \& RothfleisCH, J. (1994). Increased semantic priming in patients with dementia of the Alzheimer's type. Journal of Clinical \& Experimental Neuropsychology, 16, 608-622.

Cohen, J. D., MacWhinney, B., Flatt, M. R. \& Provost, J. (1993). PsyScope: An interactive graphic system for designing and controlling experiments in the psychology laboratory using Macintosh computers. Behavior Research Methods, Instruments, \& Computers, 25, 257-271.

Cox, D. M., Bay les, K. A., \& Trosset, M. W. (1996). Category and attribute knowledge deterioration in Alzheimer's disease. Brain \& Language, 52, 536-550.

Cronin-Golomb, A, Corkin, S., Rizzo, J. E., Cohen, J., Growdon, J. H., \& BANKS, K. S. (1991). Visual dysfunction in Alzheimer's disease: Relation to normal aging. Annals of Neurology, 29, 41-52.

Cronin-Golomb, A., Keane, M. M., Kokodis, A., Corkin, S., \& Growdon, J. H. (1992). Category knowledge in Alzheimer's disease: Normal organization and a general retrieval deficit. Psychology \& Aging, 7, 359-366.

Damasio, H., Grabowski, T. J., Tranel, D., Hichwa, R. D., \& DamaSIo, A. R. (1996). A neural basis for lexical retrieval. Nature, 380, 499505.

Davis, K. L., Price, C., Moore, P., Campea, S., \& Grossman, M. (2001). Evaluating the clinical diagnosis of frontotemporal degeneration: A reexamination of Neary et al., 1998. Neurology, 56, A144-A145.

Demb, J. B., Desmond, J. E., Wagner, A. D., Vaidya, C. J., Glover, G. H., \& Gabrieli, J. D. E. (1995). Semantic encoding and retrieval in the left inferior prefrontal cortex: A functional MRI study of task difficulty and process specificity. Journal of Neuroscience, 15, 5870-5878.

Demonet, J.-F., Chollet, F., Ramsay, S., Cardebat, D., Nespoulos, J.-L., Wise, R, RASCOL, A., \& Frackowiak, R. (1992). The anatomy of phonological and semantic processing in normal subjects. Brain, 115, 1753-1768.

Devlin, J. T., Gonnerman, L. M., Andersen, E. S., \& Seidenberg, M. (1998). Category-specific semantic deficits in focal and widespread brain damage: A computational account. Journal of Cognitive Neuroscience, 10, 77-94.

Devlin, J. T., Russell, R. P., Davis, M. H., Price, C. J., Moss, H. E., FAdili, M. J., \& TY LER, L. K. (2002). Is there an anatomical basis for category-specificity? Semantic memory studies in PET and fMRI. Neuropsychologia, 40, 54-75.

Elfgren, C., Passant, U., \& Risberg, J. (1993). Neuropsychological findings in frontal lobe dementia. Dementia, 4, 214-219.

Fisher, L. M., Freed, D. M., \& Corkin, S. (1990). Stroop color-word test performance in patients with Alzheimer's disease. Journal of Clinical \& Experimental Neuropsychology, 12, 745-758.

Flicker, C., Ferris, S. H., CrooK, T., \& Bartus, R. T. (1987). Implications of memory and language dysfunction in the naming deficit of senile dementia. Brain \& Language, 31, 187-200.

Folstein, M. F., Folstein, S. F., \& McHugh, P. R. (1975). MiniMental State: A practical method for grading the cognitive state of patients for the clinician. Journal of Psychiatric Research, 12, 189-198.

FrANCIS, W. N., \& KUČERA, H. (1982). The frequency analysis of English usage. Boston: Houghton-Mifflin.

Gainotti, G., \& Silveri, M. C. (1996). Cognitive and anatomic locus of lesion in a patient with a category-specific semantic impairment for living beings. Cognitive Neuropsychology, 13, 357-389.

Gainotti, G., Silveri, M. C., Daniele, A., \& Giustolisi, L. (1995). Neuroanatomical correlates of category-specific semantic disorders: A critical survey. Memory, 3, 247-264.

Garrard, P., Lambon Ralph, M. A., Watson, P. C., Powis, J., Pat- 
TERSON, K., \& Hodges, J. R. (2001). Longitudinal profiles of semantic impairment for living and nonliving concepts in dementia of the Alzheimer's type. Journal of Cognitive Neuroscience, 13, 892-909.

Garrard, P., Patterson, K., Watson, P. C., \& Hodges, J. R. (1998). Category specific semantic loss in dementia of Alzheimer's type: Functional-anatomic correlations from cross-sectional analyses. Brain, 121, 633-646.

Glosser, G., Friedman, R., Grugan, P. K., Lee, J. H., \& Grossman, M. (1998). Lexical semantic and associative priming in Alzheimer's disease. Neuropsychology, 12, 218-224.

Gonnerman, L. M., Andersen, E. S., Devlin, J. T., Kempler, D., \& SeIDEnberg, M. S. (1997). Double dissociation of semantic categories in Alzheimer's disease. Brain \& Language, 57, 254-279.

Grabowski, T. J., Damasio, H., \& Damasio, A. R. (1998). Premotor and prefrontal correlates of category-related lexical retrieval. NeuroImage, 7, 232-243.

Grober, E., Buschke, H., Kawas, C., \& Fuld, P. (1985). Impaired ranking of semantic attributes in dementia. Brain \& Language, 26, 276-286.

Grossman, M. (2002). Frontotemporal dementia: A review. Journal of the International Neuropsychological Society, 8, 564-583.

Grossman, M., D’Esposito, M., Hughes, E., Onishi, K., Biassou, N., White-Devine, T., \& RoBinson, K. M. (1996). Language comprehension difficulty in Alzheimer's disease, vascular dementia, and fronto-temporal degeneration. Neurology, 47, 183-189.

Grossman, M., \& Koenig, P. (in press). Semantic memory. In V. S. Ramachandran (Ed.), Encyclopedia of Cognitive Science. San Diego: Academic Press.

Grossman, M., Koenig, P., DeVita, C., Glosser, G., Alsop, D., Detre, J., \& GeE, J. (2002). The neural basis for category-specific knowledge: An fMRI study. NeuroImage, 15, 936-948.

Grossman, M., Koenig, P., Glosser, G., DeVita, C., Moore, P., Rhee, J., Detre, J., Alsop, D., \& GeE, J. (2003). Neural basis for semantic memory difficulty in Alzheimer's disease: An fMRI study. Brain, 26, 292-311.

Grossman, M., \& Mickanin, J. (1994). Picture comprehension in probable Alzheimer's disease. Brain \& Cognition, 26, 43-64.

Grossman, M., Mickanin, J., Onishi, K., Hughes, E., D'Esposito, M., Ding, X.-S., Alavi, A., \& Reivich, M. (1996). Progressive nonfluent aphasia: Language, cognitive and PET measures contrasted with probable Alzheimer's disease. Journal of Cognitive Neuroscience, 8, 135-154.

Grossman, M., \& Rhee, J. (2001). Cognitive resources during sentence processing in Alzheimer's disease. Neuropsychologia, 39, 1419-1431.

Grossman, M., Smith, E. E., Koenig, P., Glosser, G., DeVita, C., Moore, P., \& McMillan, C. (2002). The neural basis for categorization in semantic memory. NeuroImage, 17, 1549-1561.

Gustafson, L. (1993). Clinical picture of frontal lobe degeneration of non-Alzheimer type. Dementia, 4, 143-148.

HAMPTon, J. A. (1998). Similarity-based categorization and fuzziness of natural categories. Cognition, 65, 137-165.

Hart, J., \& Gordon, B. (1992). Neural subsystems for object knowledge. Nature, 359, 60-64.

Hillis, A. E., Wityk, R. J., Tuffiash, E., Beauchamp, N. J., Jacobs, M. A., Barker, P. B., \& Selnes, O. A. (2001). Hypoperfusion of Wernicke's area predicts severity of semantic deficit in acute stroke. Annals of Neurology, 50, 561-566.

Hodges, J. R., \& Patterson, K. (1996). Nonfluent progressive aphasia and semantic dementia: A comparative neuropsychological study. Journal of the International Neuropsychological Society, 2, 511-524.

Hodges, J. R., Patterson, K., Graham, N., \& Dawson, K. (1996). Naming and knowing in dementia of the Alzheimer type. Brain \& Language, 54, 302-325.

Hodges, J. R., Patterson, K., Ward, R, Garrard, P., Bak, T., Perry, R, \& Gregory,C. (1999). The differentiation of semantic dementia and frontal lobe dementia (temporal and frontal variants of frontotemporal dementia) from early Alzheimer's disease: A comparative neuropsychological study. Neuropsychology, 13, 31-40.

Howard, D., \& Patterson, K. E. (1992). Pyramids and palm trees. Bury St. Edmonds, U.K.: Thames Valley Test.

Huff, F. J., Corkin, S., \& Growdon, J. H. (1986). Semantic impairment and anomia in Alzheimer's disease. Brain \& Language, 28, 235-249.
Humphreys, G. W., \& Forde, E. M. E. (2001). Hierarchies, similarity, and interactivity in object recognition: "Category-specific" neuropsychological deficits. Behavioral \& Brain Sciences, 24, 453-509.

Johnson, M. K., \& Hermann, A. M. (1995). Semantic relations and Alzheimer's disease: An early and disproportionate deficit in functional knowledge. Journal of the International Neuropsychological Society, 1, 568-574.

Kaplan, E., Goodglass, H., \& Weintraub, S. (1983). The Boston naming test. Philadelphia: Lea \& Febiger.

Kapur, S., Rose, R., Little, P. F., Zipursky, R. B., Brown, G. M., Stuss, D., Houle, S., \& Tulving, E. (1994). The role of the left prefrontal cortex in verbal processing: Semantic processing or willed action? NeuroReport, 5, 2193-2196.

Kempler, D., Almor, A., Tyler, L. K., Andersen, E. S., \& MacDonALD, M. C. (1998). Sentence comprehension deficits in Alzheimer's disease: A comparison of off-line vs. on-line sentence processing. Brain \& Language, 64, 297-316.

Kempler, D., Andersen, E. S., \& Henderson, V. W. (1995). Linguistic and attentional contributions to anomia in Alzheimer's disease. Neuropsychiatry, Neuropsychology, \& Behavioral Neurology, 8, 33-37.

Knesevich, J. W., LaBarge, E., \& Edwards, D. (1986). Predictive value of the Boston naming test in mild senile dementia of the Alzheimer type. Psychiatry Research, 19, 155-161.

Koenig, P., Smith, E. E., Dennis, K., Moore, P., Patel, A., McMilLan, C., \& Grossman, M. (2002). Category-specific limitations in Alzheimer's disease: Process and content. Brain \& Language, 83, 136138.

Koenig, P., Smith, E. E., Moore, P., Dennis, K., \& Grossman, M. (2002). Category acquisition in Alzheimer's disease, frontotemporal dementia, and corticobasal degeneration. Neurology, 58, A353.

LaFleche, D., \& Albert, M. S. (1995). Executive function deficits in mild Alzheimer's disease. Neuropsychology, 9, 313-320.

Lambon Ralph, M. A., McClelland, J. L., Patterson, K., Galton, C. J., \& Hodges, J. R. (2001). No right to speak? The relationship between object naming and semantic impairment: Neuropsychological evidence and a computational model. Journal of Cognitive Neuroscience, 13, 341-356.

Lambon Ralph, M. A., Patterson, K., \& Hodges, J. R. (1997). The relationshipbetween naming and semantic knowledge for different categories in dementia of Alzheimer's type. Neuropsychologia, 35, 1251-1260.

Levine, D. N., LeE, J. M., \& Fisher, C. M. (1993). The visual variant of Alzheimer's disease: A clinicopathologiccase study. Neurology, 43, 305-313.

The Lund And Manchester Groups (1994). Clinical and neuropathological criteria for frontotemporal dementia. Journal of Neurology, Neurosurgery, \& Psychiatry, 57, 416-418.

MARTIN, A. (1992). Degraded knowledge representations in patients with Alzheimer's disease: Implications for models of semantic and repetition priming. In L.Squire \& N. Butters (Eds.), Neuropsychology of memory (pp. 220-232). New York: Guilford.

Martin, A., \& Fedio, P. (1983). Word production and word comprehension in Alzheimer's disease: The breakdown of semantic knowledge. Brain \& Language, 19, 124-141.

Martin, A. Wiggs, C. L., Ungerleider, L. G., \& HaXby, J. V. (1996). Neural correlates of category-specif ic knowledge. Nature, 379, 649-652.

Mauri, A., Daum, I., Sartori, G., Riesch, G., \& Birbaumer, N. (1994). Category-specific semantic impairment in Alzheimer's disease and temporal lobe dysfunction: A comparative study. Journal of Clinical \& Experimental Neuropsychology, 16, 689-701.

McKhann, G., Drachman, D., Folstein, M., Katzman, R., Price, D., \& Stadian, E. M. (1984). Clinical diagnosis of Alzheimer's disease: Report on the NINCDS-ADRDA work group under the auspices of the Department of Health and Human Services Task Force on Alzheimer's disease. Neurology, 34, 939-944.

McKhann, G., Trojanowski, J. Q., Grossman, M., Miller, B. L., DickSON, D., \& Albert, M. (2001). Clinical and pathological diagnosis of frontotemporal dementia: Report of a work group on frontotemporal dementia and Pick's disease. Archives of Neurology, 58, 1803-1809.

McRae, K., de SA, V. R. \& Seidenberg, M. (1997). On the nature and scope of featural representations for word meaning. Journal of Experimental Psychology: General, 126, 99-130. 
Medin, D. L., Goldstone, R. L., \& Gentner, D. (1993). Respects for similarity. Psychological Review, 100, 254-278.

Medin, D. L., \& Schaffer, M. M. (1978). A context theory of classification learning. Psychological Review, 85, 207-238.

Mendez, M. F., Mendez, M. A., Martin, R., Smyth, K. A., \& WhiteHOUSE, P. J. (1990). Complex visual disturbances in Alzheimer's disease. Neurology, 40, 439-443.

Mickanin, J., Grossman, M., Onishi, K., Auriacombe, S., \& Clark, C. (1994). Verbal and non-verbal fluency in patients with probable Alzheimer's disease. Neuropsychology, 8, 385-394.

Monsch, A. U., Bondi, M. W., Butters, N., \& Paulsen, J. S. (1994). A comparison of category and letter fluency in Alzheimer's disease and Huntington's disease. Neuropsychology, 8, 25-30.

Montanes, P., Goldblum, M. C., \& Boller,F. (1995). The naming impairment of living and nonliving items in Alzheimer's disease. Journal of the International Neurop sychological Society, 1, 39-48.

Montanes, P., Goldblum, M. C., \& Boller, F. (1996). Classification deficits in Alzheimer's disease with special reference to living and nonliving things. Brain \& Language, 54, 335-358.

Moore, C. J., \& Price, C. J. (1999). A functional neuroimaging study of the variables that generate category-specific object processing differences. Brain, 122, 943-962.

Moore, P., Dennis, K., McMillan, C., \& Grossman, M. (2002). Semantic category membership judgment in frontotemporal dementia (FTD) patients. Neurology, 58, A353.

Murre, J. M. J., Graham, K. S., \& Hodges, J. R. (2001). Semantic dementia: Relevance to connectionist models of long-term memory. Brain, 124, 647-675.

Neary, D., Snowden, J. S., Gustafson, L., Passant, U., Stuss, D., Black, S., Freedman, M., Kertesz, A., Robert, P. H., Albert, M., Boone, K., Miller, B. L., Cunnings, J., \& Benson, D. F. (1998). Frontotemporal lobar degeneration: A consensus on clinical diagnostic criteria. Neurology, 51, 1546-1554.

Nebes, R. D., \& Brady, C. B. (1988). Integrity of semantic fields in Alzheimer's disease. Cortex, 24, 291-300.

Nebes, R. D., \& Brady, C. B. (1990). Preserved organization of semantic attributes in Alzheimer's disease. Psychology \& Aging, 5, 574-579.

Nosofsky, R. M., \& Johansen, M. K. (2000). Exemplar-based accounts of "multiple-system" phenomena in perceptual categorization. Psychonomic Bulletin \& Review, 7, 375-402.

Nosofsky, R. M., \& PAlmeri, T. J. (1998). A rule-plus-exception model for classifying objects in continuous-dimension spaces. Psychonomic Bulletin \& Review, 5, 345-369.

Ober, B. A., Jagust, W. J., Koss, E., Delis, D. C., \& Friedland, R. P. (1991). Visuoconstructive performance and regional cerebral glucose metabolism in Alzheimer's disease. Journal of Clinical \& Experimental Neuropsychology, 13, 752-772.

Ober, B. A., \& Shenaut, G. K. (1995). Semantic priming in Alzheimer's disease: Meta-analysis and theoretical evaluation. In P. A. Allen \& T. R. Bashore (Eds.), Age differences in word and language processing (pp. 247-271). Amsterdam: North-Holland.

Ober, B. A., Shenaut, G. K., Jagust, W. J., \& Stillman, R. C. (1991). Automatic semantic priming with various category relations in Alzheimer's disease and normal aging. Psychology \& Aging, 6, 647-660.

Pasquier, F., Lebert, F., Gry monprez, L., \& Petit, H. (1995). Verbal fluency in dementia of frontal lobe type and dementia of Alzheimer type. Journal of Neurology, Neurosurgery, \& Psychiatry, 58, 81-84.

Patalano, A. L., Smith, E. E., Jonides, J., \& Koeppe, R. A. (2001). PET evidence for multiple strategies of categorization. Cognitive, Affective, \& Behavioral Neuroscience, 1, 360-370.

Pate, S. P., Margolin, D. I., Friedrich, F. J., \& Bentley, E. E. (1994). Decision-making and attentional processes in aging and in dementia of the Alzheimer's type. Cognitive Neuropsychology, 11, 321-339.

Patterson, M. B., Mack, J. L., Geldmacher, D. S., \& Whitehouse, P. J. (1996). Executive functions and Alzheimer's disease: Problems and prospects. European Journal of Neurology, 3, 5-15.

Perani, D., CAPPa, S. F., Bettinardi, V., Bressi, S., Gorno-Tempini, M., Matarrese, M., \& Fazio, F. (1995). Different neural systems for the recognition of animals and man-made tools. NeuroReport, 6, 1637-1641.

Perry, R. J., \& Hodges, J. R. (1999). Attention and executive deficits in Alzheimer's disease: A critical review. Brain, 122, 383-404.
Petersen, S. E., Fox, P. T., Posner, M. I., Mintum, M., \& Raichle, M. (1989). Positron emission tomographic studies of the processing of single words. Journal of Cognitive Neuroscience, 1, 153-170.

Pietrini, V., Nertempi, P., Vaglia, A., Revello, M. G., Pinna, V., \& Ferro-Milone,F. (1988). Recovery from herpes simplex encephalitis: Selective impairment of specific semantic categories with neuroradiological correlation. Journal of Neurology, Neurosurgery, \& Psychiatry, 51, 1284-1293.

Poldrack, R. A., Wagner, A. D., Prull, M. W., Desmond, J. E., Glover, G. H., \& Gabrieli, J. D. E. (1999). Functional specialization for semantic and phonological processing in the left inferior prefrontal cortex. NeuroImage, 10, 15-35.

Price, C., Davis, K. L., Moore, P., Campea, S., \& Grossman, M. (2001). Clinical diagnosis of frontotemporal dementia (FTD). Neurology, 56, A176.

Rahman, S., Sahakian, B. J., Hodges, J. R., Rogers, R. D., \& RobBINS, T. W. (1999). Specific cognitive deficits in mild frontal variant frontotemporal dementia. Brain, 122, 1469-1493.

Raichle, M. E., Fiez, J. A., Videen, T. O., Macleod, A.-M. K., Pardo, J. V., Fox, P. T., \& Petersen, S. E. (1994). Practice-related changes in human brain functional anatomy during nonmotor learning. Cerebral Cortex, 4, 8-26.

ReITAN, R. M. (1958). Validity of the trail making test as an indication of organic brain damage. Perceptual \& Motor Skills, 8, 271-276.

RIPS, L. J. (1989). Similarity, typicality, and categorization. In S.Vosniadou \& A. Ortony (Eds.), Similarity and analogical reasoning (pp. 2159). Cambridge: Cambridge University Press.

Rosch, E., \& Mervis, C. B. (1975). Family resemblances: Studies in the internal structure of categories. Cognitive Psychology, 3, 382-439.

Sadun, A. A., Borchert, M., DeVita, E., Hinton, D. R., \& Bassi, C. J. (1987). Assessment of visual impairment in patients with Alzheimer's disease. American Journal of Ophthalmology, 104, 113-120.

Saffran, E., \& Schwartz, M. F. (1994). Of cabbages and things: Semantic memory from a neuropsychological perspective-A tutorial review. In C. Umiltà \& M. Moscovitch (Eds.), Attention and performance XV: Conscious and nonconscious information processing (pp. 507-536). Cambridge, MA: MIT Press.

Salmon, D., Heindel, W. C., \& Lange, K. L. (1999). Differential decline in word generation from lexical and semantic categories during the course of Alzheimer's disease: Implications for the integrity of semantic memory. Journal of the International Neuropsychological Society, 5, 692-703.

Shallice, T. (1988). From neuropsychology to mental structure. Cambridge: Cambridge University Press.

Silveri, M. C., Daniele, A., Giustolisi, L., \& Gainotti, G. (1991). Dissociation between living and nonliving things in dementia of the Alzheimer type. Neurology, 41, 545-546.

Silveri, M. C., \& LegGio, M. G. (1996). Influence of disorders of visual perception in word-to-picture matching tasks in patients with Alzheimer's disease. Brain \& Language, 54, 326-334.

Smith, C. D., Anderson, A. H., Kryscio, R. J., Schmitt, F. A., Kindy, M. S., Blonder, L. X., \& Avison, M. J. (2001). Differences in functional magnetic resonance imaging activation by category in a visual confrontation naming task. Journal of Neuroimaging, 11, 165-170.

Sмiтh, E. E. (1995). Concepts and categorization. In D. Osherson \& E. E. Smith (Eds.), Invitation to cognitive science: Vol. 2. Thinking (2nd ed., pp. 1-25). Cambridge, MA: MIT Press.

SMith, E. E., \& JonidES, J. (1999). Storage and executive processes in the frontal lobes. Science, 283, 1657-1661.

Smith, E. E., Marshuetz, C., \& Geva, A. (2002). Working memory: Findings from neuroimaging and patient studies. In J. Grafman (Ed.), Handbook of neuropsychology (Vol. 7, pp. 55-72). New York: Elsevier.

Smith, E. E., \& Medin, D. L. (1981). Categories and concepts. Cambridge, MA: Harvard University Press.

Smith, E. E., \& Sloman, S. A. (1994). Similarity- versus rule-based categorization. Memory \& Cognition, 22, 377-386.

SNOWDEN, J. S. (1999). Semantic dysfunction in frontotemporal lobar degeneration. Dementia \& Geriatric Cognitive Disorders, 10, 33-36. SNowden, J. S., NeARY, D., \& MANN, D. M. (1996). Fronto-temporal lobar degeneration: Fronto-temporal dementia, progressive aphasia, semantic dementia. New York: Churchill Livingstone. 
Snowden, J. S., Neary, D., Mann, D. M. A., Goulding, P. J., \& Testa, H. J. (1992). Progressive language disorder due to lobar atrophy. Annals of Neurology, 31, 174-183.

STROop, J. R. (1935). Studies of interference in serial verbal reactions. Journal of Experimental Psychology, 18, 643-662.

Thompson-Schill, S. L., D'Esposito, M., Aguirre, G., \& Farah, M. J. (1997). Role of left inferior prefrontal cortex in retrieval of semantic knowledge: A reevaluation. Proceedings of the National Academy of Sciences, 94, 14792-14797.

TippetT, L. J., \& FARAH, M. J. (1994). A computational model of naming in Alzheimer's disease: Unitary or multiple impairments? Neuropsychology, 8, 3-13.

Tippett, L. J., Grossman, M., \& Farah, M. J. (1996). The semantic memory impairment of Alzheimer's disease: Category-specific? Cortex, 32, 143-153.

Tulving, E., Kapur, S., Craik, F. I. M., Moscovitch, M., \& Houle, S. (1994). Hemispheric encoding/retrieval asymmetry in episodic memory: Positron emission tomography findings. Proceedings of the $\mathrm{Na}$ tional Academy of Sciences, 91, 2016-2020.

Tyler, L. K., \& Moss, H. E. (2001). Towards a distributed account of conceptual knowledge. Trends in Cognitive Sciences, 5, 244-252.

WATERS, G. S., \& CAPLAN, D. (1997). Working memory and on-line sen- tence comprehension in patients with Alzheimer's disease. Journal of Psycholinguistic Research, 26, 377-400.

Waters, G. S., Rochon, E., \& Caplan, D. (1998). Task demands and sentence comprehension in patients with dementia of the Alzheimer's type. Brain \& Language, 62, 361-397.

WeCHSLER, D. (1995). Wechsler adult intelligence scale. San Antonio: Psychological Corp.

Welsh, K. A., Butters, N., Hughes, J., Mohs, R., \& Heyman, A. (1991). Detection of abnormal memory decline in mild cases of Alzheimer's disease using CERAD neuropsychological measures. Archives of Neurology, 48, 278-281.

\section{NOTE}

1. We obtained an MMSE score in $1 \mathrm{AD}$ patient at 1 month following testing because of an oversight at the time of testing. In a 2 nd AD patient, we estimated MMSE as the midpoint between the scores obtained 6 months prior to testing and 6 months after testing (1-year decline was 4 points).

(Manuscript received July 16, 2002;

revision accepted for publication May 5, 2003.) 